\title{
Staff Nurses (Nicu) Knowledge Regarding Care Of Low Birth Weight Baby
}

\author{
Ms.Rajwinder Kaur* \\ Guide: Ms. Lalita Kumari Professor cum Principal S.G.L. Nursing College Jalandhar, Punjab
}

\begin{abstract}
Low birth weight babies are immature, they need special nursing care. Nurses are front line care providers they are key persons involved with the care of the low birth weight neonates round the clock. A preexperimental study was conducted to assess the effectiveness of structured teaching programme on knowledge regarding care of low birth weight baby among (NICU) staff nurses. The study was conducted in 6 pediatrics hospitals at district Jalandhar, Punjab. Total 60 staff nurses those who met the inclusion and exclusion criteria were selected by convenience sampling technique. A pre-test was taken by using structured questionnaire followed by structured teaching programme. After 7 days post-test was taken. The overall mean score of pre-test was 15.60 with the S.D.5.98. Whereas in post-test the overall mean score of 22.68 with S.D. of 4.55 the $t$-test value was 14.46* which is statistically significant at $p<0.005$ level of significance. The study finding implied that the education had a vital role in improving the knowledge of staff nurses regarding care of low birth weight baby.
\end{abstract}

\section{Introduction}

them." "

"We need to make a world in which fewer children are born, and in which we take better care of - Max Born

Birth weight is the single most important factor determining the survival chances of the newborn. Many of the newborn die during their first year of life. The infant mortality rate is higher for all low birth weight babies than other babies. The lower the birth weight, the lower is the survival chance of the newborn.

There were1.8 million infant deaths in the world in 2003. Most of them occurred in developing countries and approximately one half took place during their neonatal period.

Low birth weight babies can be managed at the time of Antenatal period. Many mothers go on to enjoy near normal life if their babies were properly managed. Early intervention is important, especially for the management of feeding, handling, cleanliness, prevention from the infection. Mother's knowledge about care of baby reflects the health and nutritional status of the baby. Nurses play the significant role in empowering the mother of LBW with reliable method of management. Structure teaching and counseling of mothers of LBW babies by nurses may help the mother to get relieved of their worries and to join hands with the nurses in care of low birth weight babies.

\section{Need Of The Study:}

The prevalence of low birth weight exists universally in all population. Low birth weight with high mortality and morbidity continuous to be a major public health problem in India. LBW is one of the most serious challenges in maternal and child health in both developed and developing countries. Low birth weight newborn forms a pediatric priority because they have less chance of survival than babies weighing $2500 \mathrm{gm}$. Half of the prenatal and one third of infant mortality are due to the low birth weight. Low birth weight may lead to serious physical and mental handicap in those who survive. ${ }^{18}$

In India over $30 \%$ of the infants are born with low birth weight. Nearly $75 \%$ of the neonatal deaths and $50 \%$ of infant deaths occur among low birth weight baby. In India low birth weight was 30\% in year 2008, and only in Punjab state $21.3 \%$ low birth weight babies were born in year 2008 .

Further, the investigator during the clinical experience found more number of low birth weight babies born and admitted in neonatal intensive care unit. LBW newborn faces problems like hypothermia, unable to suckle at the breast and hypoglycemia. Due to lack of immunity and LBW newborn are at high risk of having problem with increased chance to acquire infection which later on can lead to death. Low birth weight babies are immature, they need special nursing care. Nurses are front line care providers they are key persons involved with the care of the low birth weight neonates round the clock. An assessment of nurse's knowledge is felt to be essential for improvement in the nursing care of low birth weight baby. So here comes the role of the nurses to assess the low birth weight babies and to protect them from various complications. Hence it is important to educate the NICU nurses about the problems and how to manage the newborn with such problems

Ms. Rajwinder Kaur, Lecturer Child Health ( Paediatric) Nursing, N.R.I. college of Nursing, Amritsar Punjab 
Nursing trends are changing with the scientific and technological growth. Nurses must acquaint themselves with the changing trends. Hence it is felt that a study on the nurse's knowledge regarding care of the low birth weight baby is a safety ladder to ensure skilled services. Thus, it is felt that the assessment of nurse's knowledge regarding care of low birth weight baby will help in ensuring skilled neonatal care which will help in decreasing the mortality rate of low birth weight baby.

\section{Statement Of Problem:}

A pre-experimental study on the effectiveness of structured teaching programme on the knowledge regarding care of low birth weight baby among Staff nurses working in Neonatal Intensive Care Units (NICU) in selected hospitals, at district Jalandhar, Punjab, 2012.

\section{Objectives:}

1. To assess the pre test knowledge of NICU staff nurses regarding care of low birth weight baby.

2. To plan and implement structured teaching programme regarding care of low birth weight baby among NICU staff nurses.

3. To assess post test knowledge of NICU staff nurses regarding care of low birth weight baby.

4. To compare pre test and post test knowledge of NICU staff nurses regarding care of low birth weight baby.

5. To find out association between knowledge of NICU staff nurses regarding care of low birth weight baby with selected socio-demographic variables

\section{Hypothesis:}

$\mathbf{H}_{\mathbf{1}^{-}}$The mean post test knowledge score of the group after structured teaching programme on knowledge regarding care of low birth weight baby among staff nurses working in NICU will be significant.

$\mathbf{H}_{\mathbf{0}^{-}}$- The mean post test knowledge score of the group after structured teaching programme on knowledge regarding care of low birth weight baby among staff nurses working in NICU will be non significant.

\section{Conceptual Framework:}

Conceptual frame work selected for this study was based on the general system theory as postulated by Von Ludwig Bertanlanfly (Marcia Stanhope, 1995).

\section{Materials And Methods}

The research design used in this study was pre experimental in nature. The study was conducted at NICU in six hospitals at district Jalandhar,Civil Hospital, Jalandhar( Punjab), Chawla Children Hospital, Jalandhar( Punjab),Sigma Hospital, Jalandhar( Punjab),Doaba Hospital, Jalandhar( Punjab),Ankur Kids Superspecialty Hospital, Jalandhar(Punjab) and Malhotra Hospital, Jalandhar (Punjab). The sample included 60 NICU staff nuses on the basis of inclusion and exclusion criteria were selected. Non probability convenience sampling technique was used for this study. The tool used for the study was the structured knowledge questionnaire consisting of section I (Socio- demographic varriables such as age, gender, professional qualification, clinical experience(years), experience in NICU (years), In-service education programme) and section II (consisting of 30 items related to knowledge regarding care of low birth weight baby). The content validity of structured questionnaire was ensured by submitting the tool to the experts in the field of paediatrics for content validation. Pilot study was conducted on 10 subjects (who were not included in the study) at S.G.L. Charitable hospital Jalandhar, Punjab. The reliability of tool was computed by applying split half technique and was calculated by Karl Pearson's coefficient of correlation formula, which was found 0.76 .

\section{A. Results And Findings}

B. Related to socio demographic Varriables of the subjects

- Study results had shown that maximum of staff nurses 28 (47\%) were in the age group 21-25 years.

- In this study $54(90 \%)$ sample were female and 06(10\%) were male.

- Majority of sample 41 (68\%) had professional qualification GNM and 07 (12\%) had B.Sc. nursing and 12 $(20 \%)$ had Post Basic B.Sc. nursing.

- Maximum number of sample $40(66 \%)$ had 0-5 years of clinical experience and minimum number of sample 07 (12\%) had 11 years and above experience and 13 (22\%) had 6-10 years of experience.

- Maximum number of 34(57\%) staff nurses had 0-2 years experience in NICU and minimum $06(10 \%)$ staff nurses had both 4-6 years and 6 and above years of experience followed by 14 (23\%) had 2-4 years experience in NICU. 
- Maximum number of sample $24(40 \%)$ were those who did not attend any in-service education programme related to care of baby and minimum $07(12 \%)$ had attended conference, $16(26 \%)$ sample were those who attended workshop and $13(22 \%)$ sample had attended seminar.

A. Related to the pre test and post test knowledge scores of (NICU) staff nurses regarding care of low birth weight baby.

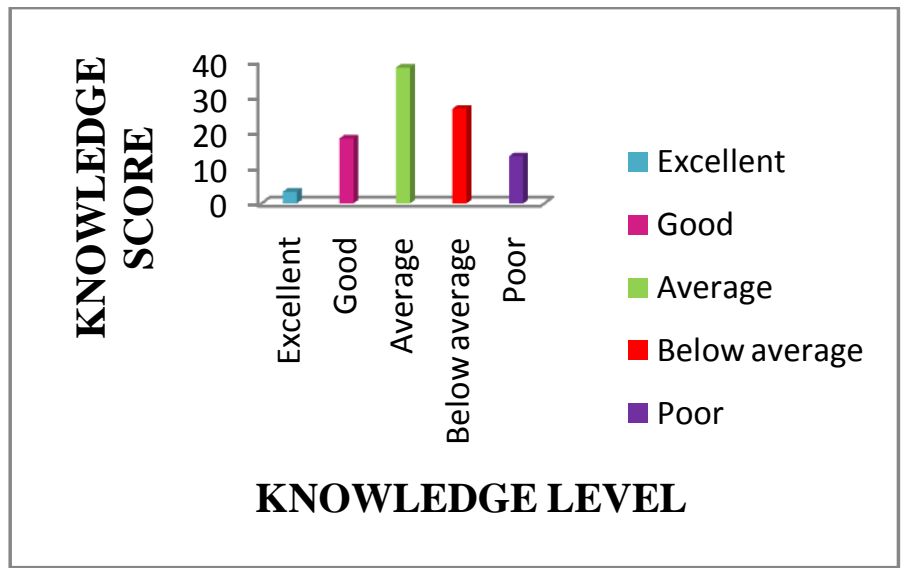

Figure 1. Pre test knowledge score of (NICU) staff nurses.

Figure 1 depict that in pre test majority of sample $38.3 \%$ nurses had average level knowledge, $26.7 \%$ had below average of knowledge, $18.3 \%$ nurses had good knowledge, $13.3 \%$ had poor knowledge and only $03.3 \%$ had excellent level of knowledge regarding care of low birth weight baby.

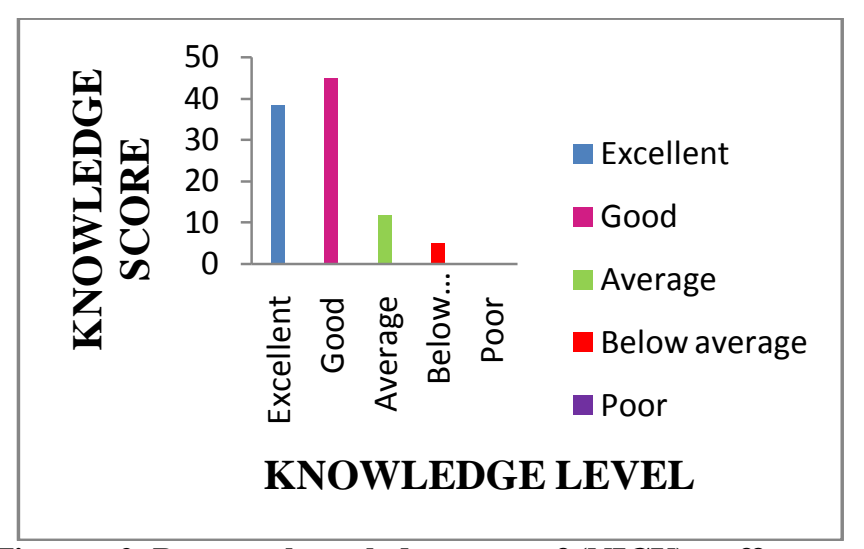

Figure 2. Post test knowledge score of (NICU) staff nurses

Table 2 Shows that in post test it was observed that $45.5 \%$ sample had good level of knowledge, $38.30 \%$ had excellent level of knowledge , $11.70 \%$ had average level of knowledge, $05.00 \%$ had below average level of knowledge and no one had poor level of knowledge after administration of STP

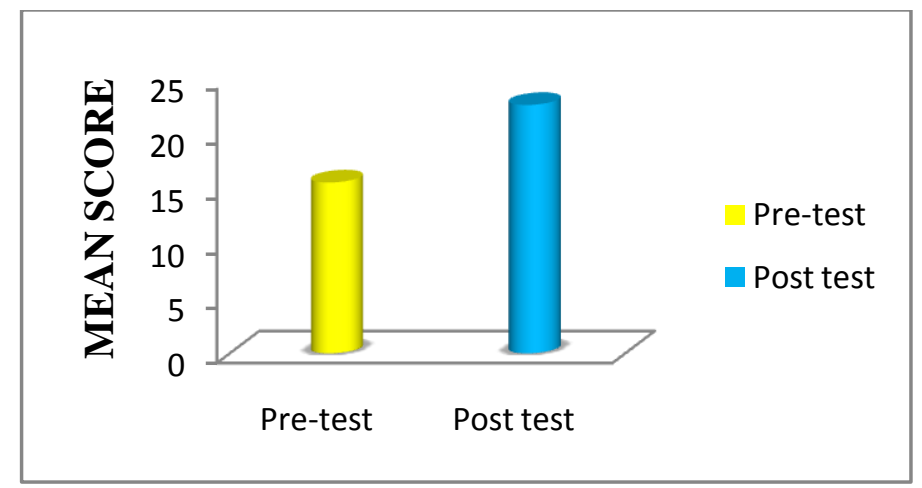

Figure 3.Comparison of pre test and post test knowledge score

Figure 3 shows that in the mean pre test knowledge score was (15.60) and post test mean knowledge score was (22.68) and. The difference between mean pre test and post test knowledge score was-7.08* significant at $\mathrm{p}<$ 
0.05 level of significance hence there was an impact of structured teaching programme on knowledge regarding Care of low birth weight baby.

\section{B. Related to the impact of Socio-demographic variables on the knowledge scores.}

All the Socio-demographic variable such as age, gender, professional qualification, clinical experience(years), experience in NICU (years), In-service education programme) had non significant association.

\section{Nursing education}

\section{Nursing Implication}

- This structured teaching programme can be utilized by the students to develop skills in creating the awareness among the nurses in selected hospitals.

- In-service education can be planned for nurses \& the other health care professionals at various levels to enable them to improve their knowledge and to gain the skills in the care of LBW baby.

- Nurses should educate the family members or care takers about monitoring of height and weight of baby at home.

Nursing practice

- The structured teaching can be utilized to create awareness among the staff nurses who doing work in neonatal intensive care units.

- Nurses are the key persons who spend maximum time with baby in NICU and provide quality care to low birth weight baby.

- Nurses should take the responsibility to teach mothers admitted in wards regarding breast feeding, warmth, personal hygiene, infection control and the general care vaccination which enables mothers to acquire insight into the care of LBW baby.

Nursing administration

- Nurse administrator may use the study findings to improve the quality of care in the community. The concept of the extended role of nurse offers many opportunities for a nurse administrator to improve the quality of life of the public and health care professionals.

- The nurse administrator in the higher level of the authority must hold discussions and meetings on the prevailing health status of the health care personnel. Based on that, the knowledge of the staff nurses can be accessed and related programme can be planned and implemented.

- Administrator should organize in-service education programmes, refresher courses and workshops for health care personnel and encourage them to participate in these activities.

Nursing research

- The findings of the study shows that the majority of the staff nurses in NICU had moderately adequate knowledge regarding the care of LBW baby. The study will motivate new researchers to conduct the same study with the different variables on a large scale.

\section{Recommendations}

- The study can be repeated on the large scale sample to validate and for better generalization of the findings.

- The study can be conducted on the large scale where equal sample are taken from each hospital.

- Comparative study can be done in different hospitals on the same topic.

\section{Conclusions}

The study findings implied that the education has a vital role in improving the knowledge of (NICU) staff nurses regarding care of low birth weight baby. Health related education is an integral part of hospital's services, structure teaching programme can play an important role in health educational programme, making the nurses an important channel for disseminating the health information to the mother's and the communities.

\section{References}

[1]. Gurav BR, Kartikeyan S, Jape RM. Low birth weight babies. Journal of pediatric.2003; 45(3): 413-415

[2]. Ghai.O.P. Essential pediatrics. $6^{\text {th }}$ edition. New Delhi: CBS Publishers, 2004.

[3]. A. Parthasaraty. IAP Textbook of Pediatrics. jaypee brothers, medical publishers(P)ltd., New Delhi.2003 pp-60-62

[4]. Parthsarthi. Text book of Paediatric. $2^{\text {nd }}$ edition, Jay Pee :61-63.

[5]. United Nations Children's Fund and the World Health Organization, Low birth weight: Country, regional and global estimates, UNICEF and WHO, New York and Geneva, 2004,pp.2-3.

[6]. United Nations Children's Fund and the World Health Organization, Low birth weight: Country, regional and global estimates, UNICEF and WHO, New York and Geneva, 2004,pp. 9. 